\title{
Unexplained childhood anaemia: idiopathic pulmonary hemosiderosis
}

\author{
KK Siu *, Rever Li, SY Lam
}

\section{A B S T R A C T}

This report demonstrates pulmonary haemorrhage as a differential cause of anaemia. Idiopathic pulmonary hemosiderosis is a rare disease in children; it is classically described as a triad of haemoptysis, pulmonary infiltrates on chest radiograph, and irondeficiency anaemia. However, anaemia may be the only presenting feature of idiopathic pulmonary hemosiderosis in children due to occult pulmonary haemorrhage. In addition, the serum ferritin is falsely high in idiopathic pulmonary hemosiderosis which increases the diagnostic difficulty. We recommend that pulmonary haemorrhage be suspected in any child presenting with iron-deficiency anaemia and persistent bilateral pulmonary infiltrates.

\section{Hong Kong Med J 2015;21:172-4}

DOI: $10.12809 / \mathrm{hkmj} 144237$

${ }^{1}$ KK Siu *, MB, ChB, MRCPCH

${ }^{2}$ R Li, MB, ChB, FHKAM (Paediatrics)

${ }^{2}$ SY Lam, MB, BS, FHKAM (Paediatrics)

Department of Paediatrics, Kwong Wah Hospital, Yaumatei, Hong Kong

2 Department of Paediatrics, Tuen Mun Hospital, Tuen Mun, Hong Kong

*Corresponding author: skk053@ha.org.hk

\section{Case report}

We report the case of a 5-year-old boy, who presented with recurrent episodes of unexplained iron-deficiency anaemia in February 2010 since the age of 27 months. Serial chest X-rays (CXRs) showed bilateral reticulonodular haziness. Bronchoalveolar lavage and lung biopsy confirmed the diagnosis of idiopathic pulmonary hemosiderosis (IPH).

The patient first presented at 27 months of age in Mainland China with malaise, loss of appetite, and shortness of breath for 10 days. He did not have fever, cough, or haemoptysis. He received two doses of H1N1 vaccination before pallor was noted. There was no history of drug or herb intake.

The presenting haemoglobin $(\mathrm{Hb})$ level was $65 \mathrm{~g} / \mathrm{L}$ (reference range [RR], 115-145 g/L), mean corpuscular volume (MCV) 84.4 fL (RR, 76-90 fL), mean corpuscular haemoglobin $(\mathrm{MCH})$ level 25.8 pg (RR, 25-31 pg), and reticulocyte count $10.4 \%$ (reference level [RL], <2\%). White cell count and platelet count were unremarkable. Blood smear showed moderate anisopoikilocytosis with polychromasia. Bone marrow aspiration and trephine biopsy revealed active marrow with erythroid preponderance.

Other investigations were performed for anaemia. Serum lactate dehydrogenase (LDH) level was elevated to $980 \mathrm{U} / \mathrm{L}$ (RL, <615 U/L). Haptoglobin level was reduced $(<0.09 \mathrm{~g} / \mathrm{L} ; \mathrm{RR}, 0.3-2.7 \mathrm{~g} / \mathrm{L})$. Direct Coombs test was negative. Bilirubin was normal. Urine for bilirubin and urobilinogen was negative. Haemoglobin pattern, serum vitamin B12, and G6PD activity were unremarkable. Serum ferritin level was $137 \mathrm{pmol} / \mathrm{L}$ (RR, 45-449 pmol/L). Antinuclear antibody assay was negative. Flow cytometry showed normal expression of CD55 and CD59 which ruled out paroxysmal nocturnal haemoglobinuria. Donath-Landsteiner antibody assay was negative, which excluded the diagnosis of paroxysmal cold haemoglobinuria.

Blood work for viral infection including antibodies to parvovirus, Epstein-Barr virus (EBV), mycoplasma, and viral titres was unremarkable.

Screening for blood loss was negative. Stool for occult blood and urine for $\mathrm{Hb}$ were negative. Red blood cell scan showed no evidence of haemorrhage.

Blood transfusion was given to correct the anaemia. Microcytic hypochromic anaemia was noted at 2 months after presentation. Haemoglobin level was $54 \mathrm{~g} / \mathrm{L}$. Mean corpuscular volume dropped from $84.4 \mathrm{fL}$ to $68 \mathrm{fL}$. Mean corpuscular haemoglobin level was $21.3 \mathrm{pg}$. Iron profile showed a low serum iron level of $3 \mu \mathrm{mol} / \mathrm{L}(\mathrm{RR}, 5-20 \mu \mathrm{mol} / \mathrm{L})$, elevated total iron-binding capacity (TIBC) of $70 \mu \mathrm{mol} / \mathrm{L}$ (RR, 37-68 $\mu \mathrm{mol} / \mathrm{L}$ ), and iron saturation of $4 \%$ (RR, 20$55 \%)$. However, the serum ferritin level was normal at $220 \mathrm{pmol} / \mathrm{L}$ (RR, 45-449 pmol/L). Iron supplement was started as a therapeutic trial for suspected irondeficiency anaemia.

$\mathrm{His} \mathrm{Hb}$ level remained stable in the next 2 years. However, in the subsequent 8 months, there were three intermittent episodes of anaemia (lowest $\mathrm{Hb}$ level, $60 \mathrm{~g} / \mathrm{L}$ ). The anaemia occurred with fever and cough which were considered symptoms of pneumonia and upper respiratory tract infection. There was no history of haemoptysis.

At 36 months after the presentation, he was admitted again for pallor, fatigue, and fever. This time, he needed oxygen therapy. Chest was clear with mild subcostal insucking. Hepatomegaly of 
$4 \mathrm{~cm}$ below the costal margin was noted. Chest $\mathrm{X}$-ray showed bilateral reticulonodular haziness (Fig 1). Haemoglobin level was $61 \mathrm{~g} / \mathrm{L}$. Both MCV (78 fL) and $\mathrm{MCH}$ level (25 pg) were in the lower normal limits. The serum ferritin level was 879 $\mathrm{pmol} / \mathrm{L}$. A diagnosis of pneumonia was made; he was started on oral co-amoxiclav (amoxicillin and clavulanic acid) and azithromycin and given blood transfusion. Fever subsided and oxygen was weaned off. Ultrasonography of abdomen performed 1 month later showed no hepatomegaly; mild hepatic coarsening was suggestive of parenchymal disease. Liver function tests were normal all along. However, the patient tested positive for EBV immunoglobulin (Ig) $\mathrm{M}$ antibodies. Thus, he was diagnosed to have pneumonia with EBV infection.

Review of old CXRs showed similar reticulonodular shadows. In view of his history of recurrent iron-deficiency anaemia and CXR findings, pulmonary hemosiderosis was suspected. Flexible bronchoscopy was performed; bronchoscopic lavage over left lingular and right middle lobe showed blood-stained fluid. Bronchoalveolar lavage yielded abundant hemosiderin-laden macrophages (HLM index, 92\%). High-resolution computed tomography of thorax showed extensive ground glass opacities and reticular shadows, suggestive of interstitial lung disease. Diffuse visceral pleural brownish deposits were noted over the entire left lung on video-assisted thoracoscopy. Lung biopsy was performed to rule out systemic disorders with pulmonary capillaritis, which could cause diffuse alveolar haemorrhage (DAH). These included Goodpasture's syndrome, IgA nephropathy, Wegener's granulomatosis, systemic lupus erythematosus, and antiphospholipid syndrome. Biopsy of lung tissue showed numerous HLM. There was no evidence of capillaritis or vasculitis. Absence of fibrosis and negative exposure history also excluded

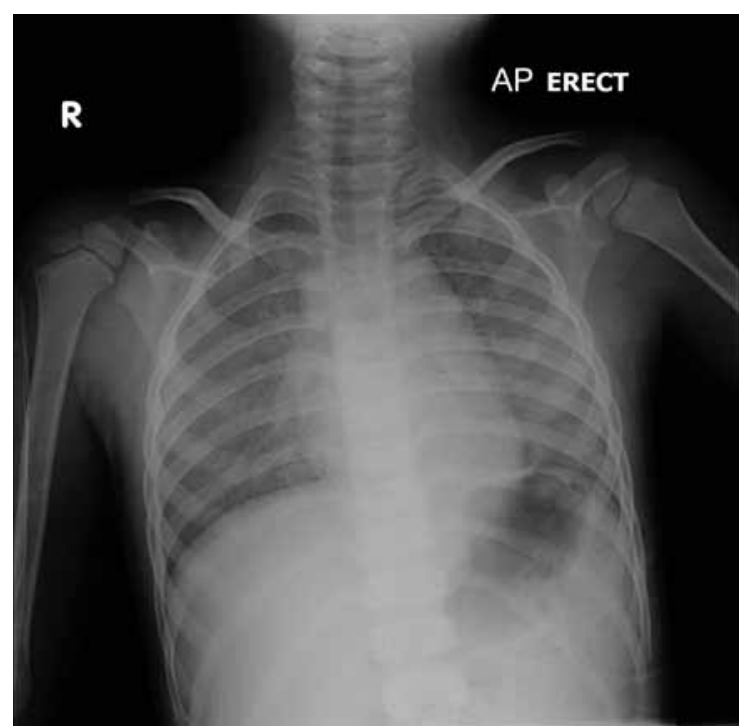

FIG I. A chest X-ray showing bilateral reticulonodular haziness

\section{兒童出現不能解釋的賓血：自發性肺鐵質沉着症 邵嘉嘉、李澤荷、林樹仁 \\ 本文指出了肺出血乃貧血的其中一個鑑別原因。自發性肺鐵質沉着症 是兒童一種罕見的疾病。根據文獻引述, 患者會有咳血、肺X線胸片 呈浸潤及缺鐵性貧血以上三個表徵。但對兒童來説, 由於有隱性肺出 血, 貧血可能是自發性肺鐵質沉着症的唯一表徵。再者, 自發性肺鐵 質沉着症患者的血清鐵蛋白會呈假性高, 增加了診斷的困難。我們建 議兒童若出現貧血及肺雙側持續呈浸潤之情況, 應及早考慮肺出血這 病因。}

hypersensitivity pneumonitis. Immunostaining for IgG, IgM, and IgA was negative. The overall picture was compatible with pulmonary hemosiderosis.

Further blood investigations were performed to exclude systemic causes of pulmonary haemorrhage as stated above. Antiglomerular basement membrane antibodies, rheumatoid factor, anti-neutrophil cytoplasmic antibodies, antinuclear antibodies, antiextractable nuclear antibodies, and anti-cardiolipin IgG antibodies were not detected. Furthermore, the patient was negative for anti-transglutaminase antibody for coeliac disease. He tested weakly positive for IgE antibodies against cow's milk. Immunoglobulin pattern was unremarkable apart from mildly raised IgA antibody level at $2.28 \mathrm{~g} / \mathrm{L}$ (range, 0.5-1.92 g/L). Renal function and urinalysis were normal.

A diagnosis of IPH was made based on the above findings. Oral prednisolone was started after the diagnosis for disease control. Chest X-ray performed after 3 months of prednisolone showed improvement in reticulonodular densities (Fig 2). We

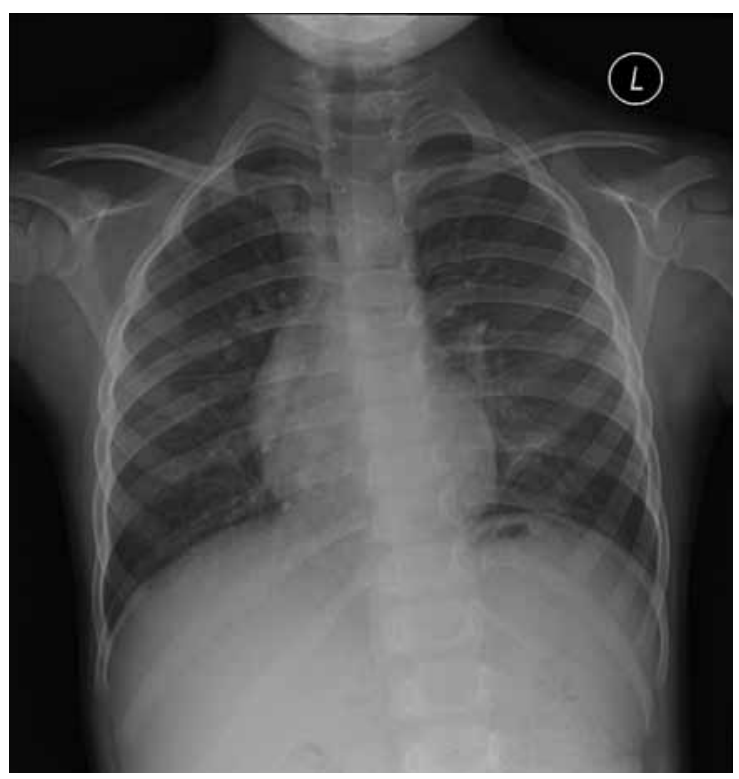

FIG 2. A chest $X$-ray performed after 3 months of prednisolone therapy showing improvement in reticulonodular densities 
plan to monitor the disease with clinical symptoms, Hb levels, LDH levels, CXRs, and spirometry.

\section{Discussion}

Idiopathic pulmonary hemosiderosis is a rare disease in children with an unknown aetiology. The estimated yearly incidence among Swedish children from 1960 through 1979 was 0.24 per 1000000 children. ${ }^{1}$ A retrospective review of records from a tertiary paediatric hospital in northern Taiwan noted five cases over 25 years. ${ }^{2}$ Patients classically presented with a triad of recurrent or chronic pulmonary symptoms (cough, dyspnoea, wheeze, haemoptysis), pulmonary infiltrates on CXR, and iron-deficiency anaemia. Our patient had only anaemia without obvious underlying causes. Subsequent CXR changes led to the suspicion of IPH.

Serum ferritin has been traditionally taken as a reliable surrogate marker of body iron stores. Hypoferritinaemia is commonly used as a diagnostic marker for iron deficiency. ${ }^{3}$ However, as it is an acutephase reactant, abnormally raised serum ferritin level may be seen during acute infection or liver disease even in the presence of iron deficiency. ${ }^{4}$ In IPH, iron study usually shows low serum iron with low iron saturation, and microcytosis and hypochromia in the blood picture. However, plasma ferritin level can be normal or elevated in IPH because of alveolar synthesis and release into the circulation and does not reflect the iron deposits in the body. ${ }^{5}$ This makes the diagnosis of iron-deficiency anaemia in IPH difficult. We recommend the use of serum iron and transferrin saturation (serum iron/TIBC) instead to evaluate suspected iron-deficiency anaemia. ${ }^{4}$

Diagnosis of IPH is based on exclusion of other causes of intrapulmonary haemorrhage and systemic diseases. In the absence of systemic disease, findings of HLM in bronchoscopic lavage or gastric aspirate/ sputum along with chronic pulmonary symptoms lead to a diagnosis of IPH. Lung biopsy is the gold standard for diagnosis. We performed lung biopsy to exclude pulmonary capillaritis, which is one of the causes of DAH. Pulmonary capillaritis is a smallvessel vasculitis, which can occur as an isolated condition or in association with multiple systemic vasculitides. Isolated DAH without identifiable causation or associated disease is referred to as IPH. ${ }^{6}$

Daily oral corticosteroids or weekly intravenous pulse methylprednisolone is commonly used in the induction treatment of IPH. Other immunosuppressive agents such as azathioprine, cyclophosphamide, and hydroxychloroquine have also been used alone or in combination with oral corticosteroids. $^{7-11}$ Low-dose oral corticosteroids, azathioprine, or methotrexate are used in maintenance phase. As there is lack of large patient series and inadequate follow-up in previous studies, the prognosis of IPH remains unclear. However, aggressive treatment with the use of corticosteroids and immunosuppressive agents are associated with a prolonged survival and improved prognosis. ${ }^{12}$ Long-term low-dose corticosteroid therapy was also reported to result in a milder disease course and prevent bleeding crisis. ${ }^{13}$

In conclusion, iron-deficiency anaemia results from poor dietary intake of iron in infants and toddlers. However, every child older than 24 months presenting with iron-deficiency anaemia should be evaluated for chronic blood loss. In this report, we have illustrated that anaemia without any respiratory symptoms can be the sole presenting feature of IPH, preceding other signs and symptoms, especially in young children. Haemoptysis may not be present in young children with IPH, as they tend to swallow their sputum. We recommend that when children present with unexplained anaemia and bilateral lung infiltrations, pulmonary haemorrhage should be suspected.

\section{References}

1. Kjellman B, Elinder G, Garwicz S, Svan H. Idiopathic pulmonary haemosiderosis in Swedish children. Acta Paediatr Scand 1984;73:584-8.

2. Yao TC, Hung IJ, Wong KS, Huang JL, Niu CK. Idiopathic pulmonary haemosiderosis: an Oriental experience. J Paediatr Child Health 2003;39:27-30.

3. Rybo E. Diagnosis of iron deficiency. Scand J Haematol Suppl 1985;43:5-39.

4. Li CH, Lee AC, Mak TW, Szeto SC. Transferrin saturation for the diagnosis of iron deficiency in febrile anaemic children. Hong Kong Pract 2003;25:363-6

5. Ioachimescu OC, Sieber S, Kotch A. Idiopathic pulmonary haemosiderosis revisited. Eur Respir J 2004;24:162-70.

6. Fullmer JJ, Langston C, Dishop MK, Fan LL. Pulmonary capillaritis in children: a review of eight cases with comparison to other alveolar hemorrhage syndromes. J Pediatr 2005;146:376-81.

7. Milman N, Pedersen FM. Idiopathic pulmonary haemosiderosis. Epidemiology, pathogenic aspects and diagnosis. Respir Med 1998;92:902-7.

8. Rossi GA, Balzano E, Battistini E, et al. Long-term prednisolone and azathioprine treatment of a patient with idiopathic pulmonary hemosiderosis. Pediatr Pulmonol 1992;13:176-80

9. Colombo JL, Stolz SM. Treatment of life-threatening primary pulmonary hemosiderosis with cyclophosphamide. Chest 1992;102:959-60.

10. Zaki M, al Saleh Q, al Mutari G. Effectiveness of chloroquine therapy in idiopathic pulmonary hemosiderosis. Pediatr Pulmonol 1995;20:125-6.

11. Bush A, Sheppard MN, Warner JO. Chloroquine in idiopathic pulmonary haemosiderosis. Arch Dis Child 1992;67:625-7.

12. Saeed MM, Woo MS, MacLaughlin EF, Margetis MF, Keens TG. Prognosis in pediatric idiopathic pulmonary hemosiderosis. Chest 1999;116:721-5.

13. Kiper N, Göçmen A, Ozçelik U, Dilber E, Anadol D. Longterm clinical course of patients with idiopathic pulmonary hemosiderosis (1979-1994): prolonged survival with lowdose corticosteroid therapy. Pediatr Pulmonol 1999;27:180-4. 